\title{
The Need For Common Terminology For Fire Safe Design Of Timber Structures
}

\section{Conference Paper}

Author(s):

Schmid, Joachim (D); Barber, David; Brandon, Daniel; Werther, Norman

Publication date:

2021

Permanent link:

https://doi.org/10.3929/ethz-b-000529570

Rights / license:

In Copyright - Non-Commercial Use Permitted 


\section{Full paper title: THE NEED FOR COMMON TERMINOLOGY FOR FIRE SAFE DESIGN OF TIMBER} STRUCTURES

\section{$\underline{\text { 1st Author }}$}

First Name: Joachim

Last Name: Schmid

Title, Affiliation: Research assistant , ETH Zürich

ORCID: https://orcid.org/0000-0002-4460-8638

\section{$\underline{\text { 2nd Author }}$}

First Name: David

Last Name: Barber

Title, Affiliation: Principal , Arup

ORCID: https://orcid.org/0000-0001-8658-8009

\section{3rd Author}

First Name: Daniel

Last Name: Brandon

Title, Affiliation: Senior Research Scientist, RISE Research Institutes of Sweden

ORCID: https://orcid.org/0000-0002-7663-1525

\section{4th Author}

First Name: Norman

Last Name: Werther

Title, Affiliation: Research assistant, TU Munich

ORCID: https://orcid.org/0000-0001-9762-1329 


\title{
THE NEED FOR COMMON TERMINOLOGY FOR FIRE SAFE DESIGN OF TIMBER STRUCTURES
}

\author{
Joachim Schmid ${ }^{1}$, David Barber ${ }^{2}$, Daniel Brandon ${ }^{3}$, Norman Werther ${ }^{4}$
}

\begin{abstract}
Timber buildings are becoming more prevalent globally and engineers and approval authorities look for suitable guidance to assist with construction. Researchers publish valuable papers on the fire safety of timber and its use for the built environment, that are being used by the engineering community at a fast pace. It has become clear to the authors that terminology specifically related to the fire safety of timber buildings is not always consistent between published research, available guidance and engineering application. This can lead to misinterpretation of published results and the applicability, potentially resulting in errors in engineering design and approval. To assist the research, engineering and approvals community this paper identifies a number of relatively commonly used terms and recommends definitions and guidance for use. The motivation is that these definitions can be adopted and be improved for clarity when they are used for education purposes or applied to the fire safety design of timber structures. Consistency in terminology use between researchers, engineers and officials can only positively assist with the continued growth of timber construction.
\end{abstract}

Keywords: fire dynamics, structural timber, terminology, fire safety engineering, cross-laminated timber

\section{INTRODUCTION}

The fire safe design of timber structures has become of global interest. As new timber structures are planned, research is published and innovative experimental testing is carried out, it gains global recognition. To enable the desired future growth in mass timber construction, engineers and approval authorities are looking for guidance on fire safe building design. Unfortunately, there are limited available resources, especially addressing higher consequence class buildings such as high-rise or large occupancies and complex construction. Researchers continue to publish valuable papers on the fire safety of mass timber and these are being used by the engineering community at a very fast pace.

Through being directly involved with mass timber research, building design and constructed projects, it has become clear to the authors that a number of missing links exist between published research, available guidance, engineering application and fire safety requirements. This can lead to misinterpretation of published results and the applicability of traditionally applied measures, potentially resulting in errors in engineering design and approval. A relatively simple solution to assist the research, engineering and approvals community is to use common terminology, based on clear definitions. This paper identifies a number of relatively commonly used terms in both research and engineering and proposes definitions for those.

\footnotetext{
${ }^{1}$ Research assistant, ETH Zürich, e-mail: schmid@ibk.baug.ethz.ch, ORCID: https://orcid.org/0000-0002-4460-8638

${ }^{2}$ Principal, Arup, e-mail: david.barber@arup.com, ORCID: https://orcid.org/0000-0001-8658-8009

${ }^{3}$ Senior Research Scientist, RISE Research Institutes of Sweden, e-mail: daniel.brandon@,ri.se, ORCID: https://orcid.org/0000-0002-7663-1525

${ }^{4}$ Title, Affiliation e-mail: Research assistant, TU Munich, email: n.werther@tum.de, ORCID: https://orcid.org/0000-0001-9762-1329
} 


\section{BACKGROUND}

For traditional structural timber buildings comprising of a limited number of unprotected timber members, the fire load introduced by the structure is considered negligible. However, where there is a larger area of exposed timber surfaces and where the building may be highly occupied, has sleeping uses or is a mid or high rise building, the traditional framework of fire resistance $(60,90,120 \mathrm{~min}$ of load bearing resistance and compartmentation, assuming a standard fire) may require re-evaluation. When large areas of structural timber are exposed to fire it contributes to the fire dynamics. Consequently, the duration of the fully developed fire and of the decay may change significantly while the maximum temperature may also exceed that of a noncombustible enclosure. Depending on the construction products, the available movable fire load and the design of the compartment, the compartment fire may go into decay or burnout. Alternatively, the fire may continue until the structural timber elements are consumed and structural failure may occur if no firefighting intervention is undertaken. Given this background and the interaction between structure and fire dynamics that specifically occurs in buildings where structural timber is exposed, the methods of determining fire safety objectives (performance goals) required by regulations, codes and standards is of utmost importance.

\section{MOTIVATION FOR NEW DEFINITIONS}

Understanding the fire dynamics within an exposed structural timber compartment and how that timber influences the fire is a significant fire safety issue and is also complex. With a number of researchers globally investigating timber fire dynamics and engineers, regulators and authorities taking up the most recent outcomes, it has become clear that there is no common terminology in use, related to mass timber construction. Examples of terms that are partly and inconsistently used include fire exposure, timber protection and encapsulation, on-set of charring, fire (heat release) decay, fire burnout, self-extinguishment, delamination, to list a few. With the lack of widely used definitions, these terms are applied to timber construction with variance and of concern is that these terms are being used incorrectly within engineering application and approvals, leading to potential safety issues or excessive requirements in construction. Without definition and the inclusion of a corresponding pass-fail criteria, the performance goals can be confused and result in very different fire design outcomes for these fire protection systems.

This paper aims to assist both the research and engineering communities by addressing a number of these shortcomings in terminology definitions for application to structural timber. By providing suggested definitions, this paper can aid those involved with timber building construction, including researchers, regulators, authorities, engineers and suppliers. The authors encourage feedback and improvements with the motivation being that these definitions would be adopted or improved for use globally and act as tool in a global harmonization and education process, for the fire safe design of mass timber structures.

\section{TERMINOLOGY AND DEFINITIONS}

\subsection{Thermal exposure and fire exposure}

In fire safety engineering, thermal exposure, might be understood as the description of the heating scenario [1] and is often used interchangeably with thermal loading, indicating the thermal conditions imposed to surfaces or surroundings. In structural engineering, the correspondent term might be the variable wind load, in that a demand is placed on the structure and an engineer needs to determine the structural response, or capacity to resist the demand.

The origin of misunderstanding seems to be a problem of engineer's perspective. From a building element point of view, where a building element is any part of the physical building form, the thermal exposure might be understood as the environmental conditions that lead to the heating of the building element produced from a certain material, or assembly of materials. Thus, the problem could be based on the thermal properties of the material only, which requires the consideration of the heat transfer within the solid (building element) due to the heating of the surface. However, the problem could be further clarified to a typical problem of building physics where the difference between an exterior and interior temperature would lead to a certain temperature profile within a building element, including a certain transition resistance [2]. The simplified transition 
resistance at the solid's surface corresponds to the convective heat transfer and the radiative losses of the building element surface, applicable in the normal and the fire situation.

From a fire dynamics point of view, the thermal exposure can be understood as the description of (1) the environment including the imposed or external heat flux and the gas temperature and (2) the interaction of this environment with the building element under consideration. The thermal exposure then comprises of the convective heat transfer for the particular surface and a surface temperature in balance with the building element (the solid) and the environment. The thermal exposure describes the applicable thermal boundary condition. In nearly all fire safety engineering analysis the natural thermal boundary condition applies [3], which is also referred to as mixed or third kind of thermal boundary condition.

Consequently, fire is not a thermal boundary condition. Based on the above discussion and in relation to timber structures, thermal exposure alone is, however, not sufficient to allow full knowledge of the fire performance of combustible building members. The similar but more general term, fire exposure, can also include nonthermal aspects of a fire, such as the oxygen concentration. Schmid et al. describe the fire exposure as thermal exposure and, additionally, the description of the gaseous environment near the combustible surface [5]. The latter comprises the oxygen concentration and the gas movement considering its velocity and the degree of turbulence. However, there is inconsistent use of both thermal exposure and fire exposure, and general agreement on how these terms are expressed is lacking.

\section{Recommendation}

Therefore, a more general term, fire exposure, is proposed for use. The definition of the term fire exposure needs to allow for replication of a fire exposure in different test setups, and also lead to the same consequences for the structure. For that purpose, experimental simulations of compartment fires in a controlled setup [4] indicate that (1) radiation temperature or incident radiant heat flux in combination with (2) oxygen concentration, provide the most important parameters to describe fire exposure. Other parameters such as gas temperature and convection conditions play a smaller role in a typical temperature range of a fire.

\subsection{Timber protection (and / or encapsulation)}

Applied fire protection to a building structure forms part of the measures to fulfil a fire safety concept (see Figure 1) aiming to achieve one or multiple functions. Timber protection as defined in this paper is a combination of boards, or wraps, or cladding or coverings that provide structural fire protection and work as a system of components, together with their fixings for a particular substrate. Coatings such as intumescent could also be a form of timber protection. Hence, timber protection may be reactive or passive, with typical applied solutions being formed from mineral-based boarding or gypsum based boarding. For clarification, fire retardant treatments to timber reduce or slow the ignition ability and flame spread at the surface, which is not considered further here as a form of timber protection.

To enhance structural performance, the timber protection may delay the onset of charring $\left(t_{c h}\right)$ and reduce the charring rate of the protected member. The goal of the timber protection may differ and can be installed to protect the timber member for some initial period or prevent heating and / or charring during the entire duration of the fire (growth and decay). Typically, timber protection that is fire rated achieves objectives described by Phase 0 and Phase 2 (see Figure 2) and the timber protection is required to remain in place on the timber member (stickability; tested according to EN 13381-7 [7]). On the contrary, non-fire rated timber protection is assumed to fail through an increase in temperature behind the protection and eventually fall-off at the onset of charring to the underlying member, followed by an increase in the rate of charring as described by Phase 3 and a return to nominal charring described by Phase 4 . The benefit of both types of timber protection (fire rated or non-fire rated) is a reduced charring depth for a certain fire duration.

A specific function that may be required by an engineer for the timber protection is described by the encapsulation period (Phase 0). The aim is to separate the combustible structural elements from a potential fire event through the full duration of the fire, therefore resulting in no change to the fire dynamics as a result of the structural timber fuel. The encapsulation period may be required for the entire duration of the fire, and this can be described by the K-classes [10]. The tested failure criteria are (i) discolouration of the substrate 
(wood based board) behind the timber protection and its joints, (ii) discolouration at and near mechanical fixings (screws, staples), (iii) a temperature limit of the temperature rise (see Recommendation

The term timber protection refers to a system (or assembly) of boards / cladding / coverings / wraps that includes the material type, fixings, joints and edge treatments. The performance of the timber protection needs to be defined by the user, with pass or fail criteria, based on the type fire exposure and time. Encapsulation is further defined with the inclusion of a pass or fail criteria, based on temperatures between the timber protection and the timber substrate, on the basis of preventing of burnt or charred timber, determined when the timber protection is exposed to a standard fire.

Table 1. Investigations have shown that discoloration around typical fasteners when fixed to solid timber or a wood-based panel would not initiate a self-propagating smouldering reaction before reaching the critical surface temperature, as measured by thermocouples [11]. Contrary to the European approach, the approach in Canada focus is solely on the assessment of the mean and maximal increase of the temperature on the substrate $\left(\Delta \mathrm{T} \leq 250^{\circ} \mathrm{C} / 270^{\circ} \mathrm{C}\right)$, (see Recommendation

The term timber protection refers to a system (or assembly) of boards / cladding / coverings / wraps that includes the material type, fixings, joints and edge treatments. The performance of the timber protection needs to be defined by the user, with pass or fail criteria, based on the type fire exposure and time. Encapsulation is further defined with the inclusion of a pass or fail criteria, based on temperatures between the timber protection and the timber substrate, on the basis of preventing of burnt or charred timber, determined when the timber protection is exposed to a standard fire.

Table 1. The afore mentioned fire tests follow the EN/ISO fire temperature-time curve $[12,13]$ and the point in time indicated in Figure 2 are valid for this assumption only. Phases 1 to 4 in Figure 2 are expected to occur in other types of fires, but guidance is currently lacking.

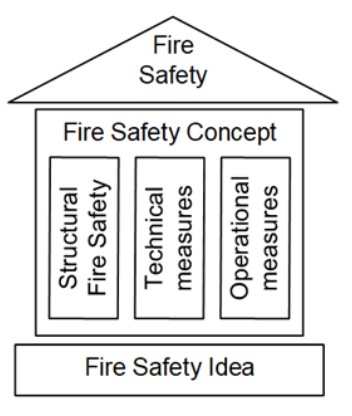

Figure 1: Elements of fire safety [8].

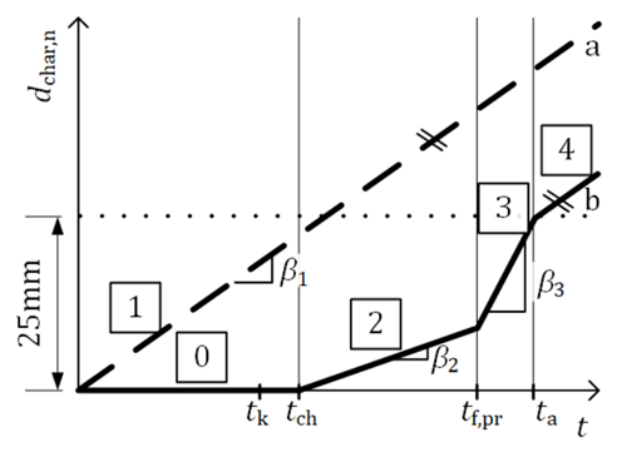

Figure 2: Charring (a) for initially unprotected timber and (b) for applied timber protection. Modified from [9].

Stricter requirements for the temperature criterion encapsulation than in Europe have been recommended in the UK through guidance published by the Structural Timber Association [12], with a temperature criteria maximum of $200^{\circ} \mathrm{C}$ at the timber substrate. This lower limit is to ensure the prevention of any pyrolysis and the release of combustible volatiles. The limit is not necessarily in line with material testing as shown in Figure 3 for a thermogravimetric (TG) analysis [15]. The derivative (DTG) shows the regions of the main decomposition processes. For mass loss, a heating rate dependency occurs, whereby the faster the heating rate, the more delayed is the pyrolysis. For $5^{\circ} \mathrm{K} / \mathrm{min}$ (blue curve), the thermal decomposition mainly occurs between 250 and $390^{\circ} \mathrm{C}$, whereas for $20^{\circ} \mathrm{K} / \mathrm{min}$ this occurs until $420^{\circ} \mathrm{C}$ (red curve). 


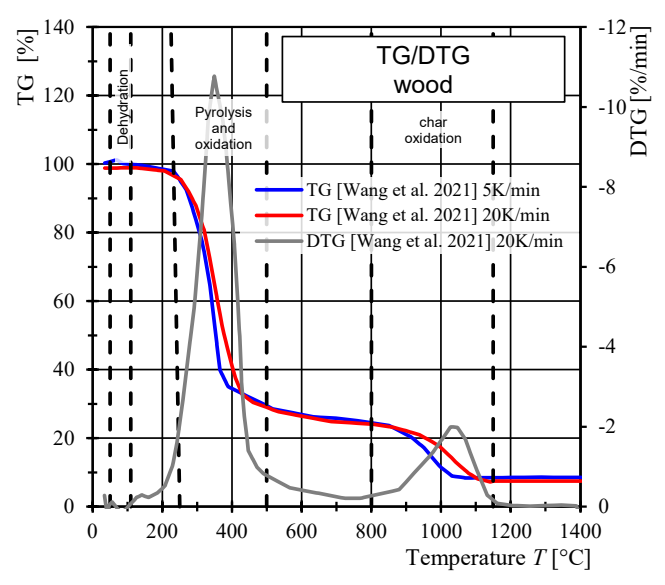

Figure 3: TGA results for two heating rates. Dehydration (dried samples), pyrolysis and oxidation and char oxidation of pinewood. Curves taken from [15].

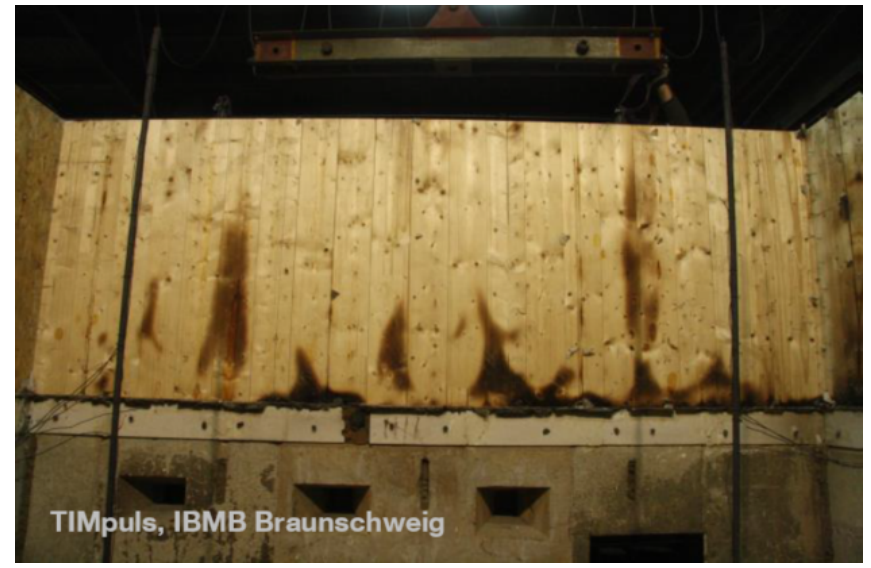

Figure 4: Previously encapsulated cross-laminated timber (CLT) surface after a parametric fire test in a compartment [16]

\section{Recommendation}

The term timber protection refers to a system (or assembly) of boards / cladding / coverings / wraps that includes the material type, fixings, joints and edge treatments. The performance of the timber protection needs to be defined by the user, with pass or fail criteria, based on the type fire exposure and time. Encapsulation is further defined with the inclusion of a pass or fail criteria, based on temperatures between the timber protection and the timber substrate, on the basis of preventing of burnt or charred timber, determined when the timber protection is exposed to a standard fire.

Table 1: Encapsulation definition according to various standard documents

\begin{tabular}{|l|l|l|l|}
\hline Criterion & $\begin{array}{l}\text { Fire protection system according to } \\
\text { EN 1995-1-2 [17] }\end{array}$ & $\begin{array}{l}\text { Encapsulation material,,K“ } \\
\text { according to EN 13501-2 [10] }\end{array}$ & $\begin{array}{l}\text { Encapsulation material } \\
\text { according to CAN / ULC S146 [18] }\end{array}$ \\
\hline $\begin{array}{l}\text { Limitation of } \\
\text { temperature } \\
\text { behind the timber } \\
\text { protection }\end{array}$ & $\begin{array}{l}\text { End of encapsulation phase: } \\
\text { Temperature limit for } \mathrm{t}_{\mathrm{ch}}(\mathrm{start} \text { time } \\
\text { of charring) } 300^{\circ} \mathrm{C}\end{array}$ & $\begin{array}{l}\text { No exceedance of the initial } \\
\text { temperature by } \\
- \text { average temperature by more } \\
\text { than } 250^{\circ} \mathrm{C} \\
- \text { maximum temperature by more } \\
\text { than } 270^{\circ} \mathrm{C}\end{array}$ & $\begin{array}{l}\text { No exceedance of the initial } \\
\text { temperature by } \\
\text { average temperature by more } \\
\text { than } 250^{\circ} \mathrm{C} \\
\text { maximum temperature by more } \\
\text { than } 270{ }^{\circ} \mathrm{C}\end{array}$ \\
\hline $\begin{array}{l}\text { Exclusion of } \\
\text { burned or charred } \\
\text { material }\end{array}$ & $\begin{array}{l}\text { Only at the surface (joints are } \\
\text { considered separately, fasteners are } \\
\text { not taken into account). }\end{array}$ & In the area of fasteners and joints & Not explicitly assessed \\
\hline $\begin{array}{l}\text { Fall-off / collapse } \\
\text { of the timber } \\
\text { protection (parts) }\end{array}$ & $\begin{array}{l}\text { Time until the cladding falls off is } \\
\text { characterized by } \mathrm{t}_{\mathrm{f}}\end{array}$ & $\begin{array}{l}\text { Fall-off or collapse (even of parts) is } \\
\text { not permitted. }\end{array}$ & Not explicitly assessed \\
\hline
\end{tabular}

\subsection{Onset of charring}

The onset of charring, also referred to as start of charring (e.g., in Eurocode, [9,17]), is often used as part of the calculation of the fire resistance and used in combination with timber protection of a building member ( $\left.t_{c h}\right)$. For example, the onset of charring can be used to determine the time of involvement of a structural timber member that is encapsulated as a fuel in a compartment fire. In the majority of the cases, this is done for standard fire exposure. The temperature criteria commonly used for the onset of charring is $300^{\circ} \mathrm{C}(\mathrm{CEN} 2004)$ It should be noted that the charring temperature in the US is rounded to $550 \mathrm{~F}$ (corresponding to $288^{\circ} \mathrm{C}$ ). For low heating rates, the charring temperature will decrease as the wood at surface undergoes a larger degree of dehydration prior to exceeding $300^{\circ} \mathrm{C}$. 
For non-standard compartment fires, the use of the start time of charring $\left(t_{c h}\right)$ is not straight forward, because the exposure may differ significantly. The onset of charring with respect to compartment fire dynamics is relevant for preventing or postponing the involvement of a member behind timber protection (initially) as it transitions to a structural fuel. In addition, the onset of charring may be used for predictions of the structural performance of timber in compartment fire conditions. Predictions of the onset of charring are commonly performed using heat transfer calculations (e.g. [6]), based on the criteria of temperature and the ignition of the timber behind the protection. As shown in Recommendation

The term timber protection refers to a system (or assembly) of boards / cladding / coverings / wraps that includes the material type, fixings, joints and edge treatments. The performance of the timber protection needs to be defined by the user, with pass or fail criteria, based on the type fire exposure and time. Encapsulation is further defined with the inclusion of a pass or fail criteria, based on temperatures between the timber protection and the timber substrate, on the basis of preventing of burnt or charred timber, determined when the timber protection is exposed to a standard fire.

Table 1, discolouration (usually at the board joints) generally occurs before the temperature criteria of $300^{\circ} \mathrm{C}$ is reached behind the timber protection.

\section{Recommendation}

The onset of charring $\left(t_{c h}\right)$ is the time a structural timber member becomes part of the fuel in a compartment fire. The temperature criteria used for the onset of charring is $300^{\circ} \mathrm{C}$.

\subsection{Fire decay for timber compartments}

Fire decay is relevant for non-standard fire exposure, i.e. where the assumption of the EN/ISO fire temperaturetime curve is not valid. The fire decay phase may be the longest stage of a fire event and is characterised through an observable decrease in the available fuel to sustain the fire, or a change in available oxygen such that no ventilation is provided. Traditionally for non-combustible structures, the fire decay can be determined through comparison of the HRR when 70\% of the movable fire load has been consumed, as suggested in [19]). For a compartment that includes structural timber elements, the decay in the fire is of significance in the determination of structural performance, given the timber structure is part of the available fuel (where the timber is not encapsulated). For a compartment with significant areas of exposed structural timber, once the moveable fuel is consumed, being the furnishings, fixtures and fittings, the timber structure may be the only fuel available to contribute to on-going heat release and will significantly influence the fire decay. Hence, for a compartment with exposed structural timber, fire decay may not occur directly after the consumption of the majority of the movable fire load, compared with a non-combustible structure compartment. For simplicity, it is recommended that the start of the decay phase is when the HRR reduces by a certain percentage, compared with the peak; or reduces by an absolute value within a certain time, compared with the peak.

It should also be noted that after fire decay, there may be fire re-growth due to other causes such as changes to ventilation (windows breaking to allow more), more fuel becomes available (failure of an internal partition or door or timber protection) or potentially the CLT type (glue line integrity failure). The occurrence of fire decay is not the same as fire burnout.

\section{Recommendation}

Fire decay is a characteristic of fire development where there is a decrease of the external and internal flaming and a reduction in the compartment temperature and heat release rate after a previous peak or steady state burning phase. Fire decay is a characteristic that may be useful to distinguish that part of the design from noncyclic burning or steady-state burning, thus, likely fire burnout should be used as a design goal rather than fire decay. Fire decay can also assist in determining firefighting objectives, noting that successful outcomes may be dependent on available equipment.

\subsection{Fire burnout}

Fire burnout may be required for some building designs to meet building regulations or codes, typically for higher consequence class buildings such as high-rise structures. Burnout of a structure should not be misunderstood as burn down (entire consumption of the structure). Fire burnout is not well defined for any type of construction material. It can be described as the consumption of $90 \%$ of the movable fuel, or the decay 
of the fire to an average compartment temperature of less than $200^{\circ} \mathrm{C}$ (where the $200^{\circ} \mathrm{C}$ is a "fire temperature" which describes the thermal exposure comprising of the contribution by both the radiation and the gas temperature). Fire burnout can also be defined through other criteria, such as moveable fuel (floor related) maximum heat release rate density (e.g. $5 \mathrm{~kW} / \mathrm{m}^{2}$ ) or an acceptable heat release rate density (e.g. $25 \mathrm{~kW} / \mathrm{m}^{2}$ ) that may be considered applicable for firefighting attack. For these fire conditions, a likely burnout can be stated but is dependent on the actual boundary conditions (ventilation, any smouldering and non-combustible structure). It should be noted that smouldering and glowing combustion may still continue and will need to be extinguished manually and corresponding measures should be developed and actioned as part of the fire strategy. A pre-condition for enabling successful manual fire extinguishment of combustible components is that the glowing or smouldering surfaces can be visually detected and reached by water (see below).

For timber structures, the burnout can also be defined based on the required structural performance of the exposed (not encapsulated) timber. The fire burnout criteria can be based on determining when the temperature in the timber members is below $100^{\circ} \mathrm{C}$, taking into account thermal penetration and transient heating, given elevated temperatures in the timber members will influence the load-carrying capacity. Fire burnout may also not occur due to changes in the compartment and availability of fuel during the decay phase, such as increased ventilation, failure of timber protection acting as encapsulation, CLT glue line integrity failure, as examples. This type of change may result in regrowth of the heat release rate and potentially lead to another flashover and a risk of cycling behaviour.

\section{Recommendation}

Where fire burnout is to be defined, this must be agreed between the design engineer and the approval authorities, to meet the required structural performance, once the fire decay phase has occurred. Fire burnout must be assessed with consideration given to the possible changes that could prevent or defer burnout occurring, such as failure of timber encapsulation, changes to available fuel and the likely occurrence of glowing and smouldering combustion. The criteria for burnout can be based on a minimum heat release rate, minimum compartment temperature or maximum temperature being reached within a timber member.

\subsection{Self-extinguishment}

The term "self-extinguishment" (sometimes self-extinction or auto-extinction) has no generally accepted definition. Despite this, it is often used as a performance goal by developers, regulators, building officials, engineers and architects, where complete fire burnout is required to be shown for high consequence buildings. Although not always clear, the definition of self-extinguishment in available literature differs significantly and may address very different combustion modes (flaming combustion and / or smouldering combustion).

Self-extinguishment of smouldering combustion of wood was studied by Ohlemiller [20], Beyler et al. [21], and Crielaard [22]. All of these authors expressed the identified extinction criterion in incident radiant heat flux, varying between $5 \mathrm{~kW} / \mathrm{m}^{2}$ [22] and $10 \mathrm{~kW} / \mathrm{m}^{2}$ [20]. Both, Crielaard and Ohlemiller, indicated the extinguishment criterion changes with airflow.

Other researchers have focussed on extinction of flaming combustion or some moment in between flaming extinction and smouldering extinction, which resulted in higher extinction criteria. Emberley [23] and Bartlett [24] expressed the extinction criterion in mass loss rate (lumped for wood and char layer) per unit area and found critical values in the same range $\left(3.48 \mathrm{~g} / \mathrm{m}^{2} \mathrm{~s}\right.$ to $\left.3.93 \mathrm{~g} / \mathrm{m}^{2} \mathrm{~s}\right)$ and Bartlett found that this criterion was insensitive to airflow. The external heat flux at extinction differed significantly in both studies, as a heat flux limit of $30.1 \mathrm{~kW} / \mathrm{m}^{2}$ was in fire propagation apparatus tests by Bartlett and $44.6 \mathrm{~kW} / \mathrm{m}^{2}$ was found in the cone calorimeter tests by Emberley. As the difference in heat flux was needed further research, it was recommended by Bartlett to use the mass loss criterion for extinction of flames.

The compartment conditions when flaming self-extinguishment occurs, with temperatures in excess of $550^{\circ} \mathrm{C}$ and radiant heat being received at the exposed timber walls or ceiling in the order of $40 \mathrm{~kW} / \mathrm{m}^{2}$, which might be used as an indicator of the start of fire decay. Reaching flaming self-extinguishment is not an indicator that the fire will definitely decay, as fire development can have periods of limited decay and then regrow, due to more fuel becoming available (see bond line integrity below). 
Some engineers tend to use the term self-extinguishment to describe a room or compartment that has zero combustion. However, the prevailing research definition for self-extinguishment of timber does not describe a compartment where the fire has decayed so that it reaches ambient temperature, nor does it mean the exposed char layer on structural timber has stopped all combustion. Unfortunately, the term self-extinguishment is often used when the actual situation being described is fire decay or fire burnout. Hence, use of the term selfextinguishment with mass timber compartments should be viewed with caution, unless it is clearly defined.

\section{Recommendation}

Self-extinguishment may be used as a performance goal for the fire design of compartments. The definition of self-extinguishment, therefore, has an impact on the building's safety and feasibility. As a performance goal, requiring self-extinguishment of flaming combustion has limited practical meaning as the incident heat flux of $40 \mathrm{~kW} / \mathrm{m}^{2}$ (corresponding to a fire temperature of roughly $550-700^{\circ} \mathrm{C}$ depending on the convection) is still structurally damaging to exposed timber. This heat flux is also significantly higher than the heat flux of ignition of timber, indicating that exposing protected timber surfaces by protection fall-off, bond line integrity failure or other phenomena will re-ignite the fire. There are multiple examples of compartment fires that re-ignited after the cessation of flames, see e.g. [25,26,27].

Self-extinguishment of smouldering combustion is significantly more challenging to achieve and may be unrealistic, though is the prevailing use of the term self-extinguishment in engineering design. Although smouldering may stop in large parts of the structure, it may continue in small gaps or enclosed locations, such as behind timber protection made from gypsum boards [28]. Arguably, continued smouldering can be caused by incidental factors, such as placement of thermally inert non-combustible material near an exposed surface. Complete, guaranteed self-extinguishment of smouldering combustion is therefore considered to be an unrealistic performance goal for building designs, given it requires firefighting intervention. The recommendation is therefore not to use self-extinguishment as a performance goal for building design, but where required to show the timber structure will retain stability through full fire development, achieve the following (a) fire decay will occur in the compartment (cooling to be superior to heating), and (b) the design of details such as joints, connections and penetrations minimises the likelihood of smouldering with manual checking an element of firefighting activities.

\subsection{Flaming combustion}

Flaming combustion occurs in timber structures with the combustion of gaseous by-products of wood pyrolysis, where the timber is exposed and not encapsulated. Flaming combustion will occur when there is an appropriate mixture of gaseous fuel and oxygen (minimum concentration of about 15\% [29]), with flames able to be auto-ignited at high gas temperatures or ignited by an external heat source. Flaming typically occurs at hot spots on wood or on the char surface [30]. A number of experiments have shown that flaming combustion on timber surfaces will continue to occur when the external heat flux at ambient is above approximately $45 \mathrm{~kW} / \mathrm{m}^{2}$ [31,32]. In the initial phase, surface flame spread impacts fire growth and where timber surfaces are exposed, the flame spread across the combustible surface needs to be understood in the context of possible compartment fire growth, with the impact on life safety. Flame spread is influenced by the orientation of the timber (vertically vs horizontally) and the configuration of the exposed timber, whether it is exposed to the compartment or within a concealed space where localised re-radiation can increase rate of spread. Building codes and standards may limit the combustibility of exposed surfaces to reduce the fire growth. For structural timber members the main source of member loss of strength is through a reduction in cross-section by the consumption of the member mass with the resultant flaming combustion and hence, flaming combustion is associated with timber structural degradation in fire. Some designers use flaming combustion extinction as a performance goal, which may not be sufficient or practical, as combustion may continue through glowing and smouldering (see section on self-extinguishment).

\section{Recommendation}

For timber structures the combustion of gaseous by-products of wood pyrolysis results in flaming, that can be auto-ignited, or ignited by an external heat source. The orientation and location of the timber will influence the spread of flaming, which may need to be further controlled to meet building codes and standards. 


\subsection{Glowing and smouldering combustion}

The occurrence of glowing and / or smouldering combustion of timber can be very important for certain types of high consequence structures, where fire burnout is required to be shown. Glowing and smouldering combustion may still occur and impact structural capacity of timber members even after fire burnout has been achieved.

Glowing combustion is the degradation in the solid phase without flames but with the emission of light from the combustion zone [21]. Smouldering combustion is a reaction between the degradation products of solid wood (mainly char) and gaseous oxygen and occurs without the emission of light. The porous structure of char allows oxygen to diffuse through it and react with it [20]. Smouldering can occur only if enough oxygen can diffuse through the char layer and for this reason, it occurs in a thin layer at the char surface. Smouldering can be identified through the visible smoke and detected by infrared or heat imaging equipment.

Both, glowing and smouldering combustion can result in re-ignition of the fire in a timber member, well after it is considered to have been extinguished. Both glowing and smouldering if allowed to occur will result in mass loss and the subsequent reduction in cross-sectional area of a timber member, therefore reducing structural capacity.

Smouldering and glowing is more prevalent at timber interfaces such as joints, connections and within small voids. It can be minimised through extra care when detailing in design with voids and cavities filled with noncombustible insulation. In various research projects, where compartment tests were performed with exposed timber it has been shown that for the limited areas tested (up to about $50 \mathrm{~m}^{2}$ ), fire services can easily extinguish glowing and smouldering combustion in timber structures. Firefighting can be slowed in the time taken to expose the timber surfaces to directly apply water, where the timber is concealed.

\section{Recommendation}

Glowing and smouldering combustion need to be recognised as part of the fire decay phase for mass timber structures. Glowing combustion occurs without flames and with the emission of light. Smouldering combustion occurs without the emission of light. Glowing and smouldering combustion need to be planned for in the design of mass timber buildings with appropriate detailing, with mitigation through firefighting.

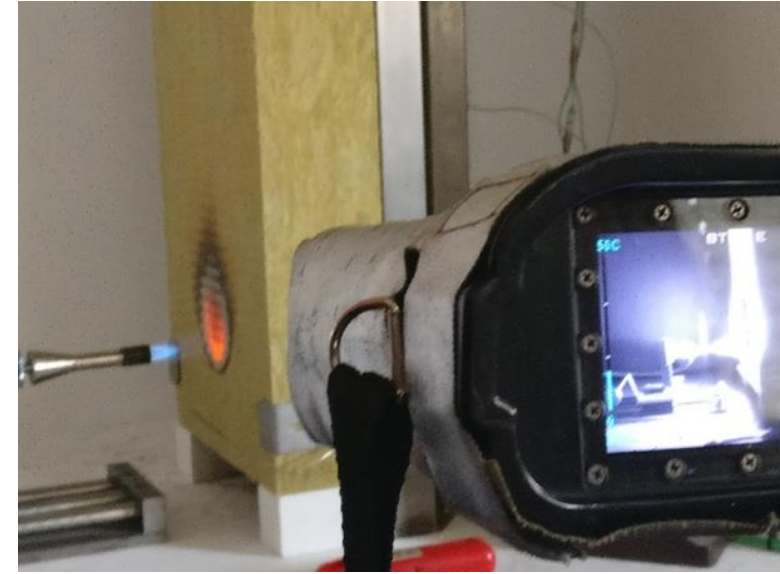

Figure 5: Initial phase of the European smouldering test EN 16733

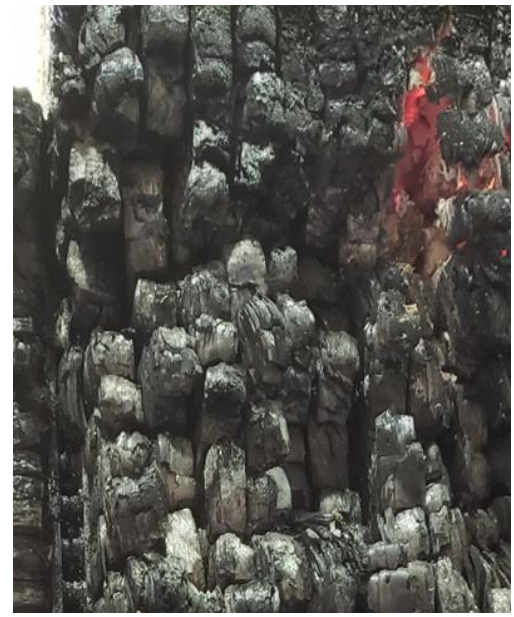

Figure 6: Glowing combustion within the char layer on a glulam column $(600 \mathrm{~mm} \times 600 \mathrm{~mm})$ after a standard fire test of $120 \mathrm{~min}$ (prior extinguishment)

\subsection{Bond line integrity}

Bond or glue line integrity failure (also referred to as fire induced debonding or fire induced delamination) is when the integrity of bond lines of glued laminated timber products is compromised in fire conditions. Weakening of the bond line can result in the fall-off of charring layers, which influences the reduction of the residual section and, thus, the load bearing capacity, but, furthermore, it can significantly influence the fire dynamics of enclosure fires [27,32]. Whether glued timber products exhibit bond line integrity failure is dependent on the exposure conditions (e.g. duration), product parameters such as the thickness of the exposed 
layer, the adhesive used and the bonding quality [34,35]. Recently, test methods to identify CLT products that do not show bond line integrity failure have been proposed [34,35,36,37].

The bond line temperature is generally agreed as being one of the important parameters affecting the bond line performance of fire exposed mass timber. However, it should be noted that available standardised bench scale elevated temperature or flame tests, such as described in DOC PS1 "Voluntary Product Standard PS 1-09 Structural Plywood", and ASTM D7247-17 [38,39], do not have the purpose of identifying bond line integrity failure in fire. Thus, these standards have not been successfully implemented to prevent bond line integrity failure in fire conditions [28]. Considering the afore mentioned influencing parameters, it is possible that a mass timber product exhibits bond line integrity failure in one fire but does not in another fire. If bond line integrity failure occurs, its effects are dependent on several properties of the fire compartment, such as opening factor ( $\mathrm{Su}$ et al. 2018), interaction between exposed surfaces, and the surface area of mass timber that exhibits bond line integrity failure. Bond line integrity has previously been identified, (a) visually, (b) using measurements of the bond line temperature [35], (c) using deviation of the charring rate with that of solid wood [37], or (d) using deviation of the mass loss rates with that of solid timber [34].

\section{Recommendation}

Recent research suggests that an average charring rate criterion that is statistically equal to the charring rate of solid timber, resulting from a standard fire exposure of $120 \mathrm{~min}$, is sufficient to rule out glue line integrity failure in the majority of flashover fires expected in real residential compartments [40].

\subsection{Potential for manual extinguishment}

For high consequence buildings constructed using mass timber the fire safety concept must address fire decay and firefighting intervention. Firefighting to prevent damage to structural building elements is most efficiently achieved in the decay phase. To enable fire extinguishment of all structural timber by manual means (firefighting), the timber char layer (surface) needs to be accessible whereby different possibilities can be considered:

Indirectly accessible surfaces: Comprises initially protected timber members where single or multiple layers of timber protection have been applied and charring has occurred during the fire. These surfaces may smoulder and heat generation may further reduce the timber protection system until fall-off. These surfaces may contribute to fire re-growth and need to be checked and their extinguishment verified.

Indirectly accessible encapsulated surfaces: Comprises of timber protection that achieves encapsulation and verification needs to be completed that no charring has occurred. Charring may still occur behind these protective surfaces, particularly near joints, or corners.

Non accessible timber surfaces: Comprises timber surfaces adjacent to small voids, located within structural connections, interfaces with structural steel or concrete members, façade interfaces and other small construction cavities and gaps. Charring may start during the fire and smouldering may continue post-fire. If undetected this may result in fire spread $[41,42,43]$. Where these interfaces, cavities and voids are created, encapsulation should be considered or sealing through proper detailing, see e.g. $[9,44]$.

\section{Recommendation}

Where the timber is exposed, either through the fire or surfaces initially protected where the timber protection has failed, can be readily extinguished. For other timber surfaces, other actions may be needed considering the actual design and the firefighting strategy.

\section{CONCLUSIONS}

Timber structures continue to be prevalent with more architects, engineers and building officials being introduced to the methods for multi-story construction. The push for codes and standards to embrace timber construction has resulted in more research and publications. Fire safety terminology specifically addressing timber structures has not been well established. To assist current and future researchers, designers and regulators, the authors have been motivated to address some of the inconsistencies in terminology through this paper. A number of terms also require definition but were beyond the limit of this paper - including char oxidation, thermal penetration depth and transient heating, for example. Definition of timber properties at 
elevated temperatures and effective timber properties that are dependent on the fire exposure would also benefit from further clarification.

\section{REFERENCES}

1. Bartlett, A.I., Hadden, R.M. \& Bisby, L.A. A Review of Factors Affecting the Burning Behaviour of Wood for Application to Tall Timber Construction. Fire Technol 55, 1-49 (2019). https://doi.org/10.1007/s10694-018$\underline{0787-y}$

2. Glaser, Helmut. Vereinfachte Berechnung der Dampfdiffusion durch geschichtete Wände bei Ausscheidung von Wasser und Eis. Kältetechnik, 1

3. Wickström U. Temperature calculation in fire safety engineering. Cham, Switzerland: Springer; 2016 Jun 16.

4. Brandon, D., Schmid, J., Su, J., Hoehler, M., Östman, B., \& Kimball, A. (2018). Experimental Fire-Simulator for Post-Flashover Compartment Fires. In SiF 2018-The 10th International Conference on Structures in Fire, Belfast, UK. New University of Ulster.

5. Schmid J, Frangi A. Structural Timber in Compartment Fires-The Timber Charring and Heat Storage Model. Open Engineering. 2021 Jan 1;11(1):435-52.

6. Brandon, D. (2018). Engineering methods for structural fire design of wood buildings: Structural integrity during a full natural fire.

7. CEN, EN 13381-7: Test methods for determining the contribution to the fire resistance of structural members Part 7: Applied protection to timber members; European standard, 2019.

8. Schmid J, Fahrni R, Klippel M, Just A. Fire design of timber structures-actual design and outlook: Estrategias de protección al fuego-Diseño y apariencia. In $1^{\circ}$ Fórum de Construcción con Madera (FMC 2019) 2019 May 24 (pp. 65-77). Forum Holzbau.

9. CEN, prEN 1995-1-2 Eurocode 5: Design of timber structures - Part 1-2: General - Structural fire design; Draft for revision, 2021.

10. CEN, EN 14135: Coverings - Determination of fire protection ability; European standard; 2004.

11. Mögele, T.: Theoretische und experimentelle Untersuchungen zum Einfluss des Befestigungssystems auf die thermische Schutzwirkung von Brandschutzbekleidungen an Holzkonstruktionen. Diploma Thesis, Technical University Munich, Germany, 2010.

12. CEN, EN 1365-1: Fire tests: General requirements; European standard, 2012.

13. ISO 834-1 Fire-resistance tests - Elements of building construction - Part 1: General requirements, 1999.

14. Structural timber buildings fire safety in use guidance Volume 6 - Mass timber structures; Building Regulation compliance B3(1), 2020.

15. Wang B, Li Y, Zhou J, Wang Y, Tao X, Zhang X, Song W. Thermogravimetric and Kinetic Analysis of HighTemperature Thermal Conversion of Pine Wood Sawdust under CO2/Ar. Energies. 2021 Jan;14(17):5328.

16. Winter, S.; Zehfuß, J.; Engel, T.; Brunkhorst, S.; Werther, N.: Brandschutztechnische Grundlagenuntersuchungen für eine erweiterte Anwendung des Holzbaus. Tagungsband Braunschweiger Brandschutz-Tage, 2019

17. CEN, EN 1995-1-2: Eurocode 5: Design of timber structures - Part 1-2: General - Structural fire design; European standard, 2004.

18. ULC CAN-S146: Standard method of test for the evaluation of encapsulation materials and assemblies of materials for the protection of structural timber elements, 2019.

19. CEN, EN 1991-1-2: Eurocode 1: Actions on structures General actions. Actions on structures exposed to fire; European standard, 2002.

20. Ohlemiller, T. J. (1991). Smoldering combustion propagation on solid wood. Fire Safety Science, 3, 565-574.

21. Beyler, C. L., Gratkowski, M. T., \& Sikorski, J. (2006). Radiant smouldering ignition of virgin plywood and plywood subjected to prolonged smouldering. In International Symposium on Fire Investigation and Technology.

22. Crielaard, R., van de Kuilen, J. W., Terwel, K., Ravenshorst, G., \& Steenbakkers, P. (2019). Self-extinguishment of cross-laminated timber. Fire Safety Journal, 105, 244-260.

23. Emberley, R., Do, T., Yim, J. and Torero, J. L. (2017) Critical heat flux and mass loss rate for extinction of flaming combustion of timber. Fire Safety Journal, 91, pp. 252-258

24. Bartlett, A. I. (2018). Auto-extinction of engineered timber (Doctoral dissertation, University of Edinburgh).

25. McGregor, C., 2013, "Contribution of Cross Laminated Timber Panels to Room Fires", Thesis, Carleton University 
26. Hadden, R., Bartlett, A., Hidalgo, J., Santamaria, S., Wiesner, F., Bisby, L., Deeny S., Lane, B., 2017, "Effects of Exposed Engineered Timber on Compartment Fire Dynamics", Proceedings of the 12th International Association of Fire Safety Science Symposium, Lund, June 10 to 16

27. Su, J., Lafrance, P. S., Hoehler, M. S., \& Bundy, M. F. (2018). Fire Safety Challenges of Tall Wood BuildingsPhase 2: Task 3-Cross Laminated Timber Compartment Fire Tests.

28. Brandon, D., Sjöström, J., Temple, A., Hallberg, E. and Kahl, F. (2021) Fire Safe implementation of visible mass timber in tall buildings - compartment fire testing. RISE Report 2021:40 Research Institutes of Sweden, Borås, Sweden.

29. Freddy Xavier Jervis Calle. Application of fire calorimetry to understand factors affecting flammability of cellulosic material: Pine needles, tree leaves and chipboard. PhD thesis, 2012.

30. Hao C. Tran and Robert H. White. Burning rate of solid wood measured in a heat release rate calorimeter. Fire and materials, 16(4):197-206, 1992.

31. Bartlett, A, Hadden, R., Hidalgo, J., Santamaria, S., Wiesner, F., Bisby, L., Deeny S., Lane, B., 2017, “Autoextinction of engineered timber: Application to compartment fires", Fire Safety Journal 91 pp 407-413

32. Emberley, R., Gorska C., Bolanosa, A., Lucherinia, A., Solartea, A., Soriguera, D., Gutierrez, M., Humphreys, K., Hidalgoa, J., Maluka, C., Law, A., Torero, J., 2017, "Description of Small and Large-scale Cross Laminated Timber Fire Tests", Fire Safety Journal 91, pp 327-335

33. Brandon, D., \& Östman, B. (2016). Fire Protection Research Foundation report:" Fire Safety Challenges of Tall Wood Buildings-Phase 2: Task 1-Literature Review".

34. Klippel, M., Schmid, J., Fahrni, R., Frangi, A., \& Lange, D. (2018). Assessing the adhesive performance in CLT exposed to fire. In World Conference on Timber Engineering.

35. Brandon D, Dagenais C. Fire Safety Challenges of Tall Wood Buildings-Phase 2: Task 5-Experimental Study of Delamination of Cross Laminated Timber (CLT) in Fire. National Fire Protection Association. NFPA report: FPRF-2018-05. 2018.

36. Janssens, M. (2017). Development of a fire performance assessment methodology for qualifying crosslaminated timber adhesives. SwRI Project, (01.23086), 01-001.

37. Craft, S., Barber, D., Klippel, M., Schmid, J., \& Frangi, A. (2018). Test Methods to Evaluate the Adhesive Performance in CLT when Exposed to Fire. In Proceedings of the 2018 World Conference on Timber Engineering. World Conference on Timber Engineering (WCTE).

38. APA PS 1-09 Voluntary product standard: Structural Plywood (with Typical APA Trademarks).

39. ASTM D7247-17, Standard Test Method for Evaluating the Shear Strength of Adhesive Bonds in Laminated Wood Products at Elevated Temperatures, ASTM International, West Conshohocken, PA, 2017, www.astm.org

40. Brandon D., Klippel M., Schmid J., Frangi A. (2021) Glue Line Integrity in Fire. Research Institutes of Sweden.

41. Just, Alar, and Daniel Brandon. "Fire Stops in Buildings." (2017), RISE report, Research Institutes of Sweden.

42. Östman B. Fire safety in modern wooden houses: mapping of fire incidents in Sweden. International fire protection. 2017(71):46-8.

43. Ostman, B., \& Stehn, L. (2014). Brand i flerbostadshus av trä-Analys, rekommendationer och FoU-behov.

44. Lignum-Dokumentation. Brandschutz. "4.1 Bauteile in Holz-Decken, Wände und Bekleidungen mit Feuerwiderstand, Lignum, 2019, Zürich." 